\title{
Interfacial Contributions in Lignocellulosic Fiber-Reinforced Polyurethane Composites
}

\author{
TIMOTHY G. RIALS, ${ }^{1}$ MICHAEL P. WOLCOTT, ${ }^{2}$ JOHN M. NASSAR ${ }^{3 *}$ \\ 'USDA-Forest Service, Southern Research Station, 2500 Shreveport Highway, Pineville, Louisiana 71360-2009, USA \\ ${ }^{2}$ Department of Civil and Environmental Engineering, Washington State University, Pullman, \\ Washington 99164-1806, USA \\ ${ }^{3}$ Temple-Inland Forest Products Corporation, Hope, Arkansas 71801, USA
}

Received 29 February 2000; accepted 22 July 2000

Published online 16 February 2001

\begin{abstract}
Whereas lignocellulosic fibers have received considerable attention as a reinforcing agent in thermoplastic composites, their applicability to reactive polymer systems remains of considerable interest. The hydroxyl-rich nature of natural lignocellulosic fibers suggests that they are particularly useful in thermosetting systems such as polyurethanes. To further this concept, urethane composites were prepared using both unused thermomechanical pulp and recycled newsprint fibers. In formulating the materials, the fibers were considered as a pseudo-reactant, contributing to the network formation. A di-functional and tri-functional poly(propylene oxide)-based polyol were investigated as the synthetic components with a polyol-miscible isocyanate resin serving as a crosslinking agent. The mechanical properties of the composites were found to depend most strongly on the type of fiber, and specifically the accessibility of hydroxy functionality on the fiber. Dynamic mechanical analysis, swelling behavior, and scanning electron micrographs of failure surfaces all provided evidence of a substantial interphase in the composites that directly impacted performance properties. The functionality of the synthetic polyol further distinguished the behavior of the composite materials. Tri-functional polyols generally increased strength and stiffness, regardless of fiber type. The data suggest that synthetic polyol functionality and relative accessibility of the internal polymer structure of the fiber wall are dominant factors in determining the extent of interphase development. Considerable opportunity exists to engineer the properties of this material system given the wide range of natural fibers and synthetic polyols available for formulation. $(\circ) 2001$ John Wiley \& Sons, Inc. J Appl Polym Sci 80: 546-555, 2001
\end{abstract}

Key words: wood fiber; polyurethane; composite; interphase; dynamic mechanical analysis

\section{INTRODUCTION}

Wood and wood fiber composites have traditionally been used in load-bearing applications that

\footnotetext{
Correspondence to: T. G. Rials.

Formenly Graduate Research Assistant, Division of For estry, West Virgmia Unversity, Morgantown, WV $26506-6125$

Joumal of Applied Polymer Science, $V_{0}$. $80,546-555(2001)$ 02001 , John Whey \& Sons, lne
}

rely on highly crosslinked adhesives like phenolformaldehyde and urea-formaldehyde resins for mechanical support. ${ }^{1}$ In recent years, however, wood fibers have been applied to a variety of alternative material systems. For example, the strength, toughness, and aspect ratio of these fibers has spurred considerable use in reinforcing for thermoplastics. ${ }^{2,3}$ These wood--plastic composites are dominated by component incompatibility, and the absence of reactivity leads to weak inter- 
facial properties. ${ }^{4-6}$ Despite the significance assigned to interfacial structure, surprisingly little attention has been given to using wood fibers as a component in reactive composite formulations.

Polyurethane represents one polymer class for investigating the effect of reactivity on interfacial structure and properties. Isocyanates have been widely used as a binder for conventional wood composites. ${ }^{7,8}$ Although the improved strength, water resistance, and durability of isocyanatebonded wood composites have routinely been attributed to covalent bonding with the fiber cell wall polymers, considerable speculation remains around the precise adhesion mechanism. ${ }^{9-11}$ Little research has directly addressed polyurethane adhesion in wood ${ }^{12}$ or the role of wood as a component in a polyurethane. ${ }^{13}$

Preliminary investigations into polyurethanes incorporating natural fibers as a reactive component established the importance of fiber/polyol interaction on composite morphology and behavior. ${ }^{14}$ The objective of this research was to further define the behavior of polyurethane composites formulated with lignocellulosic fibers of different origins. The accessible range of mechanical properties is evaluated with respect to composite morphology as influenced by formulation variables including the functionality of the synthetic polyol component.

\section{MATERIALS AND METHODS}

\section{Raw Materials}

Urethane composites were produced by using two types of wood fibers: 1 . an unprocessed thermomechanical pulp (TMP) and, 2. recycled newsprint obtained from a commercial source. Clean, ink-free rolls of waste paper were wet and shredded to produce pulp using a mechanical device described previously by Liang et al. ${ }^{15}$ All fibers were dried at $105^{\circ} \mathrm{C}$ in a forced-air oven to a constant weight before use. An apparent hydroxyl number was determined for the fibers using a modified ASTM D1638-74 standard, following the procedure outlined by Wang. ${ }^{13}$

The composites were formulated using either a di-functional or tri-functional poly(propylene oxide)-based polyol, and a polyol miscible, isocyanate prepolymer (Blendur-5000) as a crosslinking agent (Bayer, Inc. Pittsburgh, PA). Both the wood fiber and poly(propylene oxide) polymers were treated as polyols and mixed to ratios of 50:50 and
Table I Characteristics of Synthetic and Fiber Polyols

\begin{tabular}{lcc}
\hline Polyol Type & $\begin{array}{c}\text { Molecular } \\
\text { Weight } \\
\text { (Nominal) }\end{array}$ & $\begin{array}{c}\text { Hydroxyl } \\
\text { Number }\end{array}$ \\
\hline Triol & 3000 & 54 \\
Diol & 3000 & 56 \\
Virgin fiber & - & 173 \\
Recycled fiber & - & 74 \\
\hline
\end{tabular}

70:30 (fiber/polyol), by weight. For reference, composites of only wood fiber and isocyanate were also produced. An isocyanate index of 1.25 was used to accommodate the proportion of isocyanate required for all composite formulations. A summary of relevant characteristics of the components is given in Table I.

\section{Composite Manufacture}

Specified weights of polyol and isocyanate were blended to ensure thorough mixing of the resin. Dry fibers were weighed and sprayed with the premixed polyol/isocyanate resin using an air atomized spray head mounted in a vented blending drum. Fiber mats were manually formed in a $34-\mathrm{cm}$ square vacuum-forming box. After prepressing, the mat was placed onto Teflon ${ }^{\circledR}$-coated plates, and surrounded with a square aluminum dam to control panel thickness and restrict resin flow. The panels were pressed to a target thickness and density of $4 \mathrm{~mm}$ and $0.75 \mathrm{~g} / \mathrm{cm}^{3}$, respectively. The press parameters used for the individual panels are presented in Table II.

\section{Composite Characterization}

The mechanical properties of the composites were determined by using a servo-hydraulic universal testing machine equipped with computer acquisition for load and displacement. Static bending tests were conducted in accordance with ASTM D-1037. Dynamic mechanical properties of the composites were evaluated with a Rheometrics, Inc. (Piscataway, NJ) RSA-II instrument. All tests were conducted with a three-point bending configuration on samples measuring $12 \times 4 \mathrm{~mm}$ $(W \times T)$ with a $48-\mathrm{mm}$ span. The storage modulus $\left(E^{\prime}\right)$, loss modulus $\left(E^{\prime \prime}\right)$, and $\tan \delta$ were measured at five-degree intervals from -70 to $200^{\circ} \mathrm{C}$, with a constant frequency of $1 \mathrm{~Hz}$. Scanning electron micrographs of composite fracture surfaces were 
Table II Press Parameters Used to Manufacture Fiber-Based Polyurethane Panels

\begin{tabular}{|c|c|c|c|c|c|}
\hline Fiber Type & Ratio WF/PO & Polyol Type & $\begin{array}{c}\text { Platen } \\
\text { Temperature }\left({ }^{\circ} \mathrm{C}\right)\end{array}$ & $\begin{array}{l}\text { Press Time } \\
\quad(\min )\end{array}$ & $\begin{array}{c}\text { Press } \\
\text { Venting }\end{array}$ \\
\hline \multirow[t]{5}{*}{ TMP Fiber } & $50: 50$ & Triol & 177 & 6 & No \\
\hline & $70: 30$ & Triol & 177 & 6 & Yes \\
\hline & $100: 0$ & - & 177 & 6 & Yes \\
\hline & $50: 50$ & Diol & 177 & 8 & No \\
\hline & $70: 30$ & Diol & 177 & 8 & Yes \\
\hline \multirow[t]{5}{*}{ ONP Fiber } & $50: 50$ & Triol & 218 & 4.5 & No \\
\hline & $70: 30$ & Triol & 218 & 4.5 & Yes \\
\hline & 100:0 & - & 218 & 4.5 & Yes \\
\hline & $50: 50$ & Diol & 177 & 8 & No \\
\hline & $70: 30$ & Diol & 177 & 8 & Yes \\
\hline
\end{tabular}

recorded on an Amray Model AMR-800 (Bedford, MA) scanning electron microscope. The samples were prepared by vapor deposition of a gold-palladium alloy.

To further evaluate network morphology, the swelling behavior of the composites in various solvents was evaluated. Samples measuring 20 $\times 8 \times 4 \mathrm{~mm}$ in size were obtained from each panel and soaked in the solvent until a constant weight was achieved. After measuring the swollen weight and volume, the samples were dried and reweighed. Sol fraction and percent swell were calculated as a fraction of the original sample weight. Tetrahydrofuran (THF) $\left(\delta=9.1 \mathrm{~cm}^{3} / \mathrm{cal}\right)$, dimethylformamide (DMF) $\left(\delta=12.1 \mathrm{~cm}^{3} / \mathrm{cal}\right)$, ethanol $\left(\delta=12.7 \mathrm{~cm}^{3} / \mathrm{cal}\right)$, and water $(\delta=23.1$ $\mathrm{cm}^{3} / \mathrm{cal}$ ) were selected as swelling agents based on the solubility behavior of the individual components.

\section{RESULTS AND DISCUSSION}

\section{Mechanical Properties}

Lignocellulosic urethanes are of interest in part because of the wide range of properties available by appropriately selecting raw materials. Figure 1 illustrates the variation in mechanical properties with fiber content and polyol type, revealing substantially different behavioral patterns. The flexural strength [modulus of rupture (MOR)] and stiffness [modulus of elasticity (MOE)] increase with fiber content, fiber type, and polyol functionality. In all cases, mechanical properties increased dramatically with fiber content. However, when compared with the fiber regenerated from
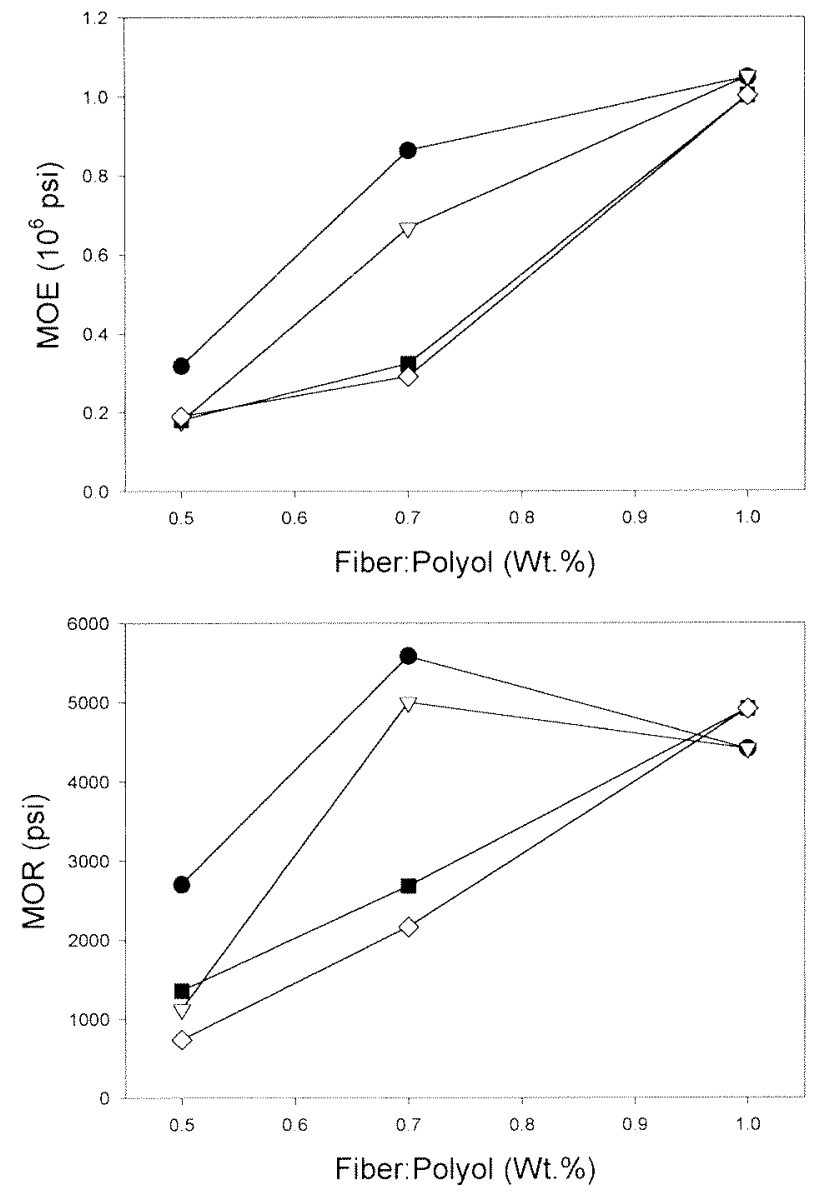

Figure 1 Effect of fiber type and polyol functionality on the variation of modulus of elasticity (MOE) (top) and modulus of rupture (MOR) (bottom) with fiber to synthetic polyol weight ratio. ( TMP/triol, ( $\nabla) \mathrm{TMP} /$ diol, (a) ONP/triol, and ( $\diamond)$ ONP/diol. 
old newsprint (ONP), the unprocessed TMP fiber yielded a composite with uniformly higher properties. This difference is most significant at the median (0.70) fiber/polyol ratio. At the extremes of the composition range studied (fiber/polyol $0.50,1.0)$, differences in mechanical behavior are insignificant.

From the standpoint of a urethane formulation, the primary difference between the fiber types is in the apparent hydroxyl number, or reactivity, of the fiber. This high hydroxyl number for the TMP fiber appears to have the largest influence at 0.7 fiber/polyol ratios. Functionality of the synthetic polyol only influences the properties of composites prepared with TMP fibers. In this case, the triol yields materials that are of consistently higher stiffness than those produced with the diol.

MOR of the urethane composites displays similar trends to MOE, although the differences are slightly magnified. At a fiber/polyol ratio of 0.7 , the unprocessed, TMP fiber composites have a MOR nearly $21 / 2$ times that of the ONP composites. The tri-functional polyol increases the MOR by approximately $10 \%$ in both fiber systems. As with the MOE, the fiber type displays the most significant influence at a 0.7 fiber/polyol fraction. At this point it is important to recall the large difference in isocyanate requirements resulting from the variation in hydroxyl number of the TMP and ONP fiber polyols. This factor may contribute, in part, to the large variation in mechanical properties found in the materials produced from the two fibers, but cannot account entirely for the experimental observations. Instead, the results suggest that accessibility of the interior structure of the fiber wall may play a much more important role in determining composite properties. Both the synthetic diol and triol have similar molecular weight and similar hydroxyl number, yet the tri-functional polyol leads to consistently higher strength and stiffness. This may reflect differences in cell wall solubility of the polyols that facilitate diffusion of the diol into the cell wall matrix of the TMP fiber, leading to more ineffective crosslinks. In contrast, the recycled fiber, with a more extensively hydrogen-bonded surface structure restricts penetration and results in a much sharper fiber/synthetic phase boundary and a high crosslink density region near the fiber surface. This impact on interfacial structure and morphology would be clearly represented in ultimate properties of the composites, as is the case. At a fiber/polyol ratio of 0.5 , defin-
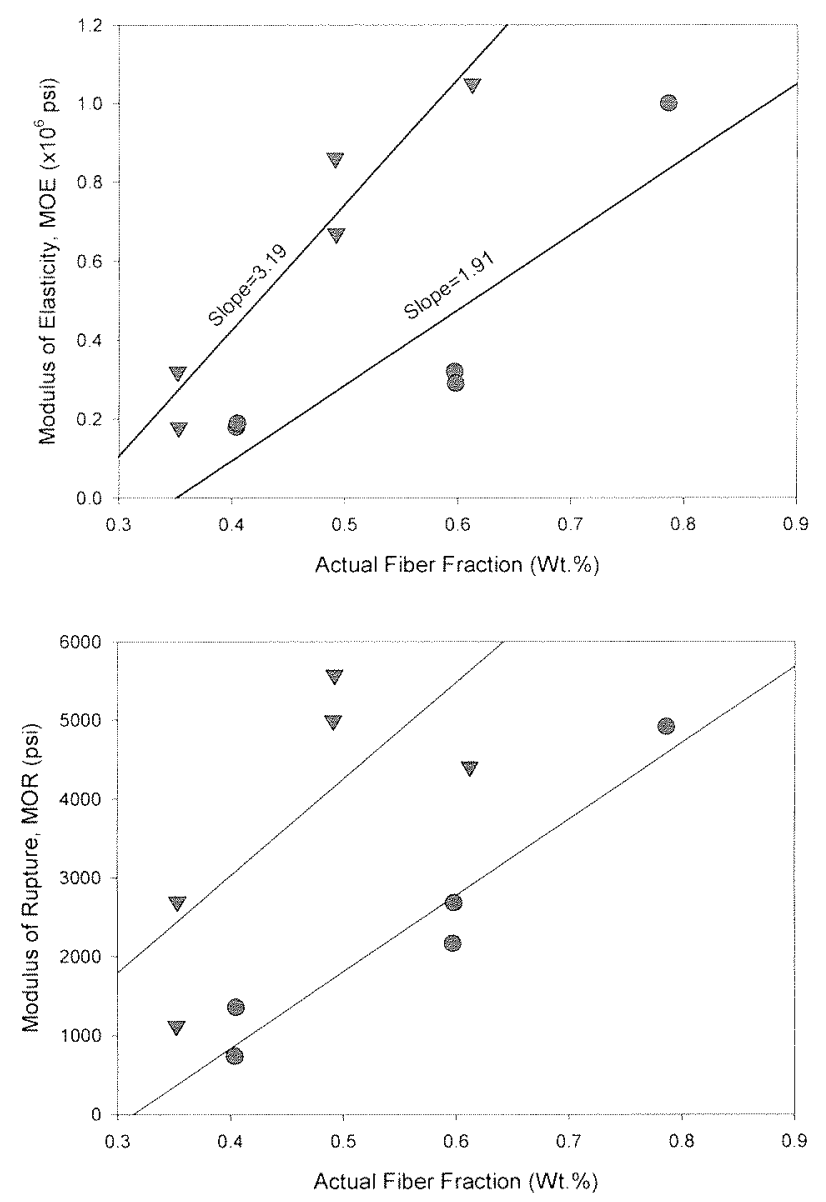

Figure 2 Variation in MOE (top) and MOR (bottom) with fiber weight fraction. ( $)$ TMP fiber, and ( ) ONP fiber.

ing the point where interfacial volume is maximized relative to the pure phases, the MOR difference for composites prepared with the two synthetic polyols is greatest.

A slightly different view of the effect of formulation variables on composite mechanical properties is presented in Figure 2. In this figure, MOE and MOR are plotted against the actual weight fraction of fiber in the formulation. It should not be surprising that a strong correlation exists between fiber content and the mechanical property of interest in virtually all instances. This is particularly true for the stiffness of composite samples prepared with both TMP and ONP fibers. This treatment of the data offers some indication of the fiber efficiency factor, which suggests a substantial difference between the two raw materials. A factor of 3.19 and 1.91 is found for the TMP and ONP composites, respectively. It is tempting to assign the observed differences to 

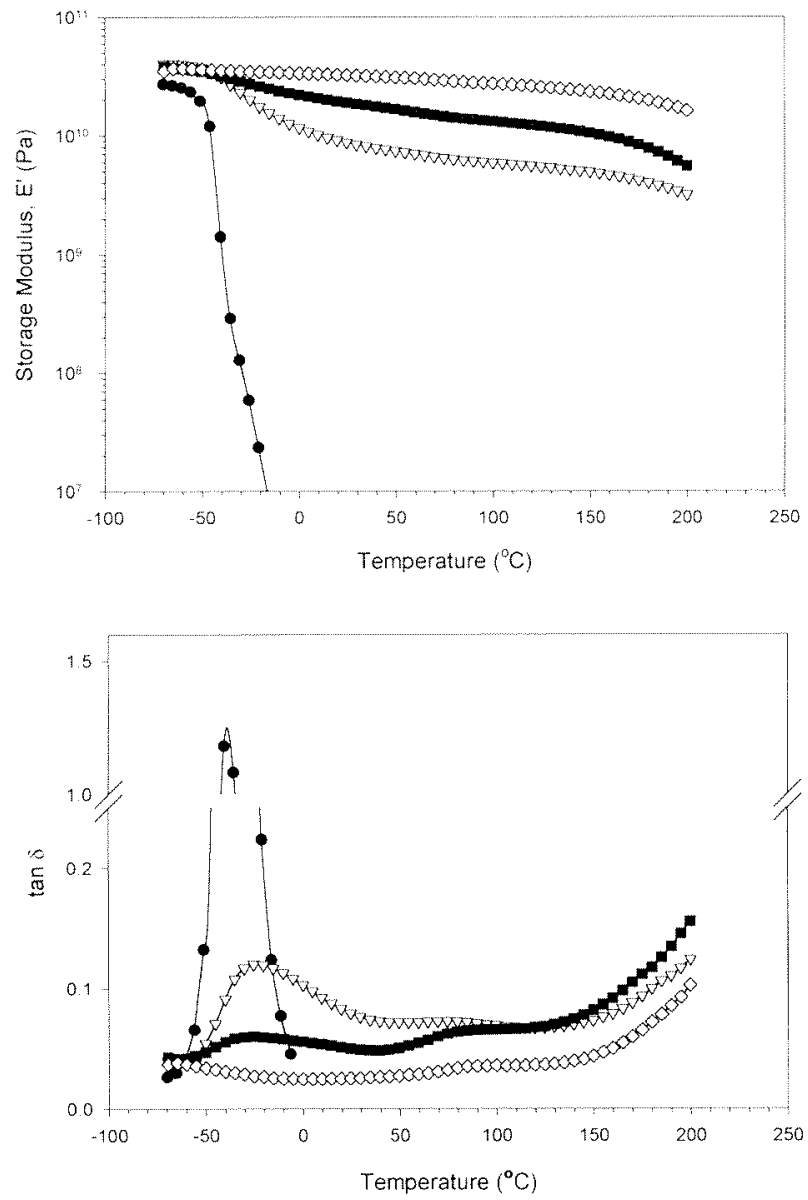

Figure 3 Effect of fiber content on the variation of storage modulus ( $E^{\prime}$, top) and $\tan \delta$ (bottom) with temperature for TMP/triol composites. Fiber/polyol ratio:

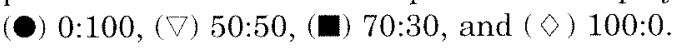

greater strength and stiffness of the unprocessed TMP fiber; however, literature reports have suggested very little difference in the mechanical properties of these fiber types. Groom et al. ${ }^{16}$ have determined the mean Young's modulus of loblolly pine fibers as $11.6 \times 10^{6} \mathrm{kPa}$ compared with 10.4 $\times 10^{6} \mathrm{kPa}$ for recycled newsprint. Consequently, it is difficult to strictly assign the observed differences to MOE variation in the fiber component. Also, the relationship is diminished significantly for the unprocessed TMP fiber composite. This provides further evidence of differences in the composites' interfacial structure that depends on fiber type and, to a lesser extent, synthetic polyol functionality.

\section{Composite Morphology and Structure \\ Dynamic Mechanical Analysis}

Dynamic mechanical analysis was used to explore the phase composition of the fiber composites and provide insight into its role in determining mechanical properties. The dynamic mechanical properties, storage modulus $\left(E^{\prime}\right)$ and $\tan \delta$, of materials produced with unprocessed TMP fibers and the tri-functional polyol are shown in Figure 3. The spectrum of the unfilled polyurethane prepared with the triol alone is included for comparison. The unfilled urethane exhibits a sharp drop in storage modulus, corresponding to a $\tan \delta$ maximum, at $-40^{\circ} \mathrm{C}$, characteristic of the glass transition of this rubbery polymer. In contrast to this single event, the $\tan \delta$ spectra for the TMP/triol composites reveal three distinct relaxation processes. The relaxations include a low temperature $\tan \delta$ peak at approximately $-25^{\circ} \mathrm{C}\left(\alpha_{1}\right)$, a weak transition $(\beta)$ at intermediate temperatures (ca. $80^{\circ} \mathrm{C}$ ), and the onset of a high temperature transition $\left(\alpha_{2}\right)$ at approximately $150^{\circ} \mathrm{C}$. The $\alpha_{1}$ and $\alpha_{2}$ relaxation processes can readily be assigned to
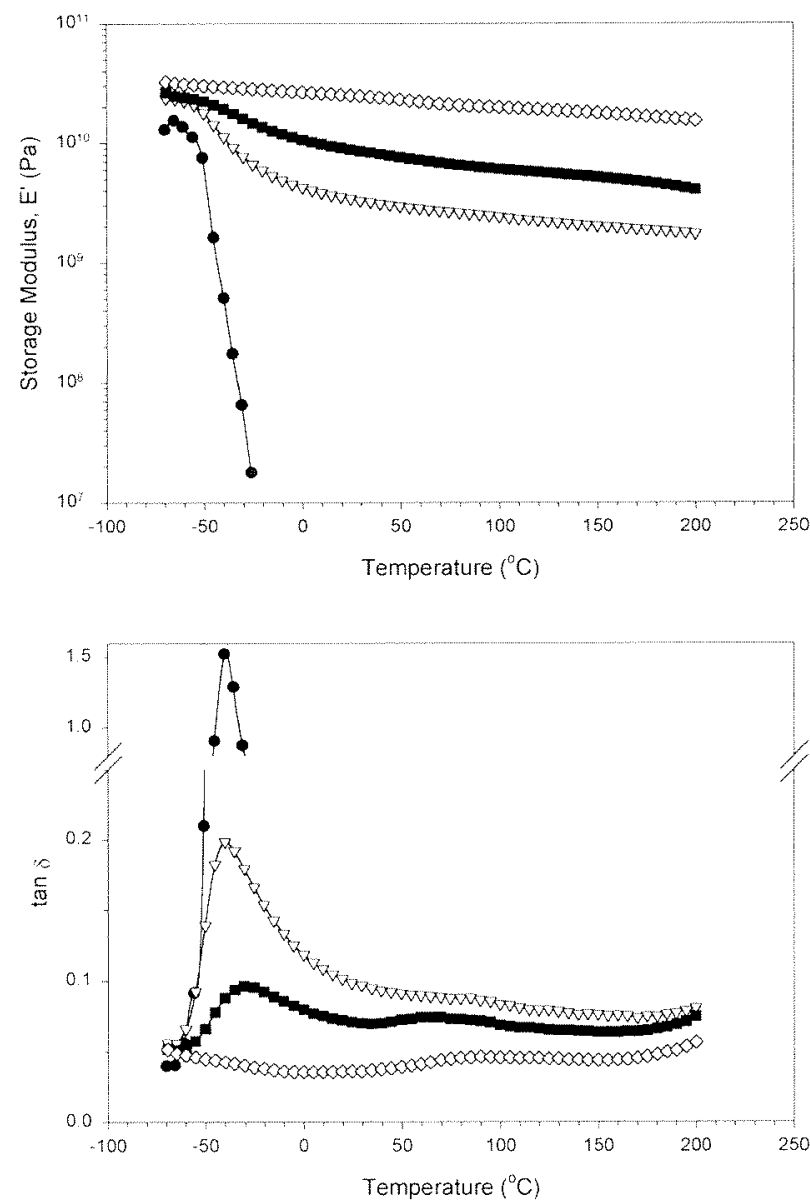

Figure 4 Effect of fiber content on the variation of storage modulus ( $E^{\prime}$, top) and $\tan \delta$ (bottom) with temperature for ONP/diol composites. Fiber/polyol ratios: (-) $0: 100,(\nabla) 50: 50,(\mathbf{a}) 70: 30$, and $(\diamond)$ 100:0. 
Table III Effect of Formulation Variables on the Low Temperature ( $\left.\alpha_{1}\right)$ Transition and Storage Modulus at $100^{\circ} \mathrm{C}$ in Fiber-Based Urethane Composites

\begin{tabular}{|c|c|c|c|c|c|c|c|c|c|}
\hline \multirow[b]{3}{*}{$\begin{array}{l}\text { Fiber } \\
\text { Type }\end{array}$} & \multirow[b]{3}{*}{$\begin{array}{l}\text { Fiber/ } \\
\text { Polyol }\end{array}$} & \multicolumn{4}{|c|}{ Di-Functional Polyol } & \multicolumn{4}{|c|}{ Tri-Functional Polyol } \\
\hline & & \multicolumn{3}{|c|}{$\operatorname{Tan} \delta$} & \multirow{2}{*}{$\begin{array}{c}E^{\prime}(100) \\
\times 10^{9} \\
\left(\text { dynes } / \mathrm{cm}^{2}\right)\end{array}$} & \multicolumn{3}{|c|}{$\operatorname{Tan} \delta$} & \multirow{2}{*}{$\begin{array}{c}E^{\prime}(100) \\
\quad \times 10^{9} \\
\left(\text { dynes } / \mathrm{cm}^{2}\right)\end{array}$} \\
\hline & & $\begin{array}{c}T_{\text {peak }} \\
\left({ }^{\circ} \mathrm{C}\right)\end{array}$ & Peak & Slope $^{\mathrm{a}}$ & & $\begin{array}{c}T_{\text {peak }} \\
\left({ }^{\circ} \mathrm{C}\right)\end{array}$ & Peak & Slope ${ }^{a}$ & \\
\hline $\begin{array}{l}\text { Unfilled } \\
\text { ONP }\end{array}$ & $0: 100$ & -39.7 & 1.53 & - & - & -39.6 & 1.24 & - & - \\
\hline Fiber & $\begin{array}{l}50: 50 \\
70: 30\end{array}$ & $\begin{array}{l}-39.9 \\
-30.3\end{array}$ & $\begin{array}{l}0.197 \\
0.097\end{array}$ & $\begin{array}{l}2.75 \\
1.00\end{array}$ & $\begin{array}{l}2.41 \\
6.06\end{array}$ & $\begin{array}{l}-30.3 \\
-24.8\end{array}$ & $\begin{array}{l}0.197 \\
0.125\end{array}$ & $\begin{array}{l}4.00 \\
1.75\end{array}$ & $\begin{array}{l}4.40 \\
7.52\end{array}$ \\
\hline \multicolumn{10}{|l|}{ TMP } \\
\hline Fiber & $\begin{array}{l}50: 50 \\
70: 30\end{array}$ & $\begin{array}{l}-30.3 \\
-30.2\end{array}$ & $\begin{array}{l}0.173 \\
0.062\end{array}$ & $\begin{array}{l}0.90 \\
0.10\end{array}$ & $\begin{array}{l}2.81 \\
1.13\end{array}$ & $\begin{array}{l}-25.4 \\
-25.4\end{array}$ & $\begin{array}{l}0.119 \\
0.059\end{array}$ & $\begin{array}{l}1.25 \\
0.40\end{array}$ & $\begin{array}{c}5.90 \\
13.1\end{array}$ \\
\hline
\end{tabular}

a Maximum slope $\left(d \tan \delta / d T, \times 10^{-3}\right)$ of the high temperature side of the $\alpha_{1}$ peak reflecting the breadth of the transition.

the glass transition temperature $\left(T_{g}\right)$ of the synthetic polyol phase and the $T_{g}$ of the fiber cell wall polymers (lignin and hemicellulose), respectively. The source of the intermediate transition, $\beta$, is more difficult to identify; however, this transition has been reported for several wood composite systems, and attributed to either a crystalline cellulose relaxation or an iso-viscous point relating to fiber-fiber contacts. ${ }^{17}$ Wang $^{13}$ has reported a similar transition in urethanes based on xylan and $\alpha$-cellulose, which he assigned to the urethane bond to the wood components. Considerable speculation remains around the origin of this relatively weak relaxation process in the spectra, except to identify the wood fiber as the source.

Several interesting insights can be gained from closer inspection of the spectra at the temperature extremes. For the low temperature transition, $\alpha_{1}$, the addition of TMP fiber (50 wt \%) increases the transition temperature about $10^{\circ}$ and dramatically reduces the $\tan \delta$ maximum associated with this phase. Furthermore, the relaxation process is skewed to higher temperatures, concluding at about $40^{\circ} \mathrm{C}$. This trend continues as fiber content increases, with the transition becoming absent for the 100\% TMP composite. This behavior suggests that an extensively bonded interphase is established at the fiber surface, and is further supported by the trends found for the $\alpha_{2}$ process. In dry wood, the onset of the amorphous component $T_{w}$ is typically not found at temperatures lower than $190^{\circ} \mathrm{C}$. The observed onset is nearly $40^{\circ}$ below this point, indicating some plasticization of the fiber wall polymers. It is unclear, however, whether this is because of copolymerization or simple physical mixing of the low $T_{g}$ polyol with the fiber. This observation does furnish clear evidence of an intimate association between the fiber and synthetic polyol components in the formulation, and is consistent with previously published observations. ${ }^{14}$

The effect of temperature on the dynamic mechanical properties of composites prepared with recycled fiber (ONP) and di-functional polyol is shown in Figure 4. As temperature is increased from -70 to $-20^{\circ} \mathrm{C}$, the $T_{g}$ of the unfilled polyurethane is reached and its storage modulus decreases dramatically with the onset of sample flow. The addition of fiber reduces the magnitude of the decline and retains strength at higher temperature. The plateau modulus increases directly with fiber content, indicating an extensively bonded network. The high temperature moduli of these composites is consistently lower than that found for the TMP/triol composites, presumably as a consequence of differences in network structure, interfacial interaction, or both.

The tan $\delta$ spectra of the materials provide some perspective on composite structure. The most prominent event is the $\alpha_{1}$ relaxation located at $-40^{\circ} \mathrm{C}$ for the unfilled polyurethane. As the fiber content is raised, this transition (originating from the synthetic polyol phase) decreases dramatically in intensity, and gradually increase in temperature to a maximum near $-30^{\circ} \mathrm{C}$. The presence of ONP fiber also results in a high temperature shoulder. This observation, coupled with the reduction in peak intensity, indicates that a sig- 
Table IV Summary of Equilibrium Swelling and Percent Solubles for Polyurethane Composites Prepared with Different Amounts and Type of Fiber, and Different Synthetic Polyols

\begin{tabular}{|c|c|c|c|c|c|c|}
\hline & \multicolumn{3}{|c|}{$\begin{array}{l}\text { Unprocessed TMP Fiber } \\
\text { (\% Swell/\% Solubles) }\end{array}$} & \multicolumn{3}{|c|}{ Recycled ONP Fiber (\% Swell/\% Solubles) } \\
\hline & 50 & 70 & 100 & 50 & 70 & 100 \\
\hline \multicolumn{7}{|l|}{ Diol } \\
\hline THF & $122.4 / 24.8$ & $74.2 / 0.8$ & $49.1 / 0.1$ & $105.6 / 33.6$ & $79.1 / 1.8$ & $59.3 / 0.2$ \\
\hline EtOH & $69.0 / 19.2$ & $57.7 / 1.5$ & $60.9 / 0.1$ & $107.8 / 30.6$ & $85.1 / 1.6$ & $73.1 / 0.1$ \\
\hline DMF & $212.6 / 26.7$ & $114.8 / 4.9$ & $109.9 / 1.9$ & $178.8 / 26.6$ & $125.8 / 1.8$ & $135.8 / 0.49$ \\
\hline Water & $30.8 / 1.54$ & $52.3 / 4.54$ & $29.9 / 2.61$ & $42.8 / 0.98$ & $63.7 / 0.63$ & $56.7 / 0.64$ \\
\hline \multicolumn{7}{|l|}{ Triol } \\
\hline THF & $92.6 / 1.5$ & $74.5 / 0.7$ & $49.1 / 0.1$ & $122.2 / 13.5$ & $65.7 / 0.5$ & $59.3 / 0.2$ \\
\hline $\mathrm{EtOH}$ & $56.4 / 1.5$ & $52.5 / 1.1$ & $60.9 / 0.1$ & $81.0 / 16.2$ & $73.0 / 0.6$ & $73.1 / 0.1$ \\
\hline DMF & $131.4 / 3.22$ & $130.0 / 3.94$ & $109.9 / 1.95$ & $149.8 / 16.15$ & $126.7 / 0.75$ & $135.8 / 0.49$ \\
\hline Water & $31.3 / 1.89$ & $55.4 / 2.99$ & $29.9 / 2.61$ & $44.4 / 0.48$ & $42.4 / 0.41$ & $56.7 / 0.64$ \\
\hline
\end{tabular}

nificant proportion of the synthetic phase is removed from the relaxation process. This formulation is clearly distinguished from the TMP/triol materials by the effective absence of the $\alpha_{2}$ transition at high temperatures. The differences in dynamic mechanical behavior can be explained by more efficient diffusion of the low molecular weight polyol/isocyanate resin into the cell wall of the unprocessed TMP fiber. The diffusion process results in a much more extensive interphase by broadening the phase boundary into the fiber interior. This leads to improved properties.

The effect of component variables on certain characteristics of the low temperature, $\alpha_{1}, \tan \delta$ peak and the plateau modulus is summarized in Table III. Interpretation of the data reveals three trends supporting the view that composite properties are derived from both network formation and interfacial structure: 1 . $T_{g}$ variation with fiber content and type, 2. $T_{g}$ variation with polyol functionality, and 3. peak broadening with both polyol functionality and fiber type. The increasing $T_{g}$ with fiber content exhibits distinctive trends for the materials produced with the different fiber types. Whereas the TMP composites exhibit a rapid increase in $T_{g}$ for all fiber additions studied, the $T_{g}$ of the ONP composites increases more gradually with fiber level. In addition, the $T_{g}$ of composites produced with triol are 5 to $9^{\circ}$ higher than the same formulations produced with the diol despite similar $T_{g}$ s for the unfilled polymers. The damping capacity of the materials also exhibits differences when using different polyol and fiber types. A dramatically reduced $\tan \delta$ maximum is associated with all levels of fiber addition but is lower for materials produced with TMP and those produced with the tri-functional polyol. An associated increase in transition breadth is also apparent. Finally, the high temperature modulus is consistently higher for composites prepared with the TMP fiber with maximum properties developing when the tri-functional polyol is included.

Definitive interpretation of the data is difficult as a result of variables that have not been accounted for directly. For example, fiber polymer fragments could serve as a polyfunctional component to increase crosslinking of the synthetic phase and elevate the $T_{g}$. This factor would be expected to elevate $T_{g}$ with fiber (and polymer fragment) content, which is not the case for the TMP composites. Instead, the observed trends in the $\alpha_{1}$ transition suggest that two mechanisms may be responsible for the observed behavior. First, the $T_{g}$ increase in the ONP composites is gradual because of an increased chain density at the fiber surface. The increased surface area results in increases in the volume fraction of the highly crosslinked interface region that elevates $T_{v}$. Alternatively, the TMP behavior may be attributed to increased penetration and access to the internal wall polymers of the fiber, creating a more extensive interphase with higher crosslinking.

\section{Swelling Behavior}

The inherent heterogeneity and multiphase character of this composite limits the quantitative utility of swelling experiments; however, even a 
relative assessment of crosslink density, and the distribution of crosslinks within the individual phases are interesting. The swelling solvents were selected to provide a wide solubility parameter range and to interact with the individual components. Water is a strong swelling agent for the hydrophilic fibers, whereas ethanol is a good swelling agent for the synthetic urethane, and dimethylformamide is a powerful swelling solvent for both components. Focusing on the percent solubles found for the composites (Table IV), it is not surprising that the extractable fraction declines rapidly with increasing fiber levels. Relatively large amounts of material were removed from the composites produced with a 0.5 fiber/ polyol ratio, indicating incomplete network formation. This observation was particularly true for the materials prepared with the di-functional polyol, and for the recycled ONP fiber composites. In contrast, the sol fraction was very low for the TMP/triol system. This suggests the development of a more homogeneous network system, and is consistent with earlier observations on dynamic mechanical properties.

The variation in swelling behavior with formulation is shown in Figure 5 for three of the solvents investigated. The clearest separation of the four composite systems is provided by ethanol. Generally, the extent of swelling by ethanol decreases as the fiber content of the material is increased. At all fiber compositions, the recycled ONP composites exhibit significantly higher swelling than the materials prepared with the TMP fibers. In addition, within each of the fiber groups, the diol formulations swell more than those composites formulated with the tri-functional polyol. A similar trend can be identified for the materials when swollen using dimethylformamide; however, the effect of polyol functionality on the degree of swelling is amplified for the TMP-based samples. Notice, too, the slight change in the trend for the TMP/triol. Swelling the samples in water presents an interesting contrast to that of the other two swelling solvents. In this instance, the percent swell reaches a maximum at $70 \%$ fiber for the composites derived from the unprocessed, TMP fibers. The type of polyol also has a dramatic effect on the swelling response of the recycled fiber materials. Whereas the general pattern for water holds in the diol formulations, the tri-functional polyol results in an inverted pattern with the percent swell reduced significantly.
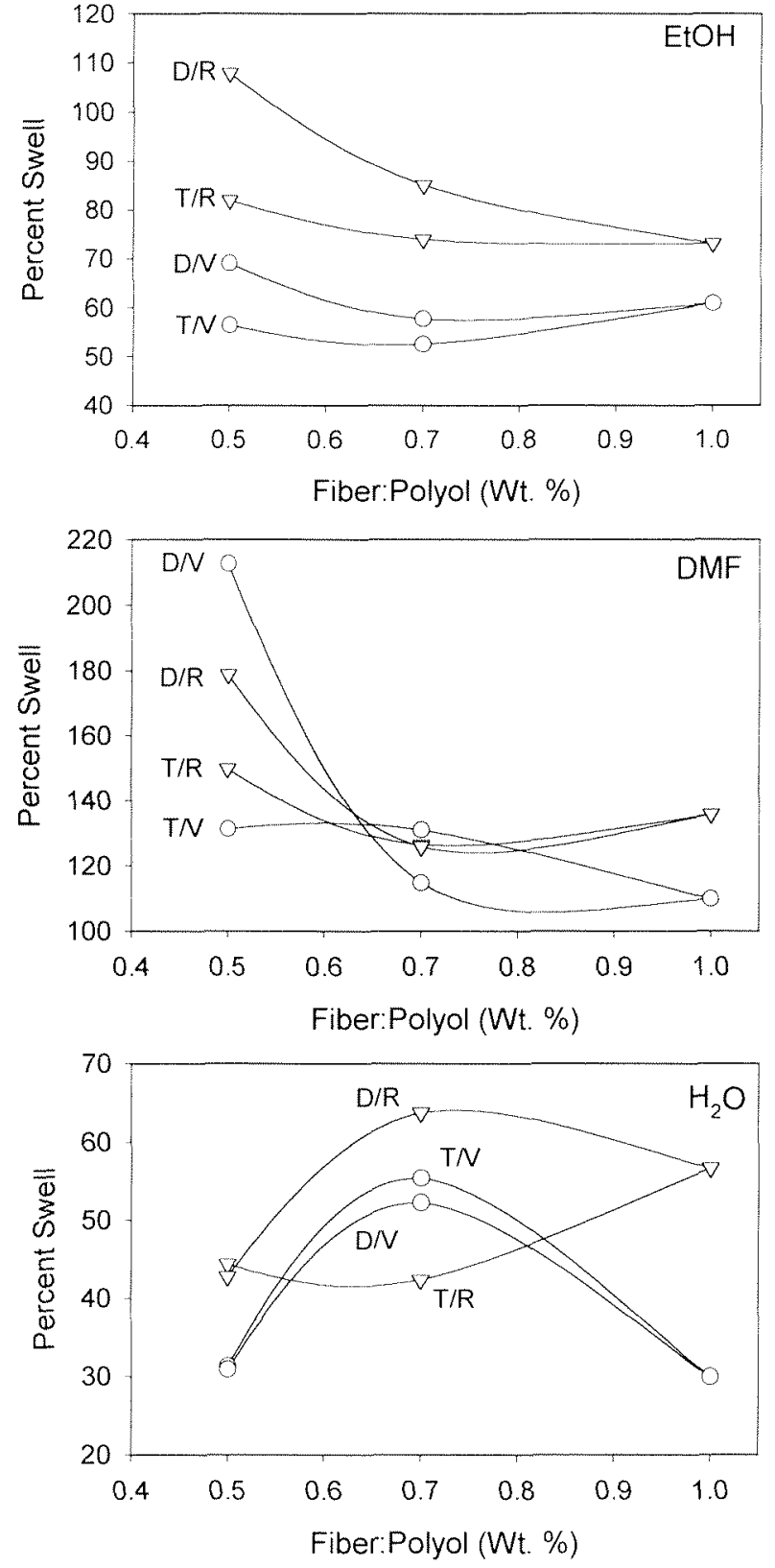

Figure 5 Effect of fiber-to-polyol ratio on the degree of swelling for polyurethane composites prepared with different fiber type and polyol functionality.

Interpreting the swelling data is not straightforward beyond the general insights provided by ethanol. Recognizing that the degree of swelling is inversely related to the extent of crosslinking in the fiber composite, the data suggest that the crosslink density increases essentially with polyol functionality, both synthetic and natural. The lowest crosslink density is found for the diol/ONP system whereas the highest crosslink density oc- 

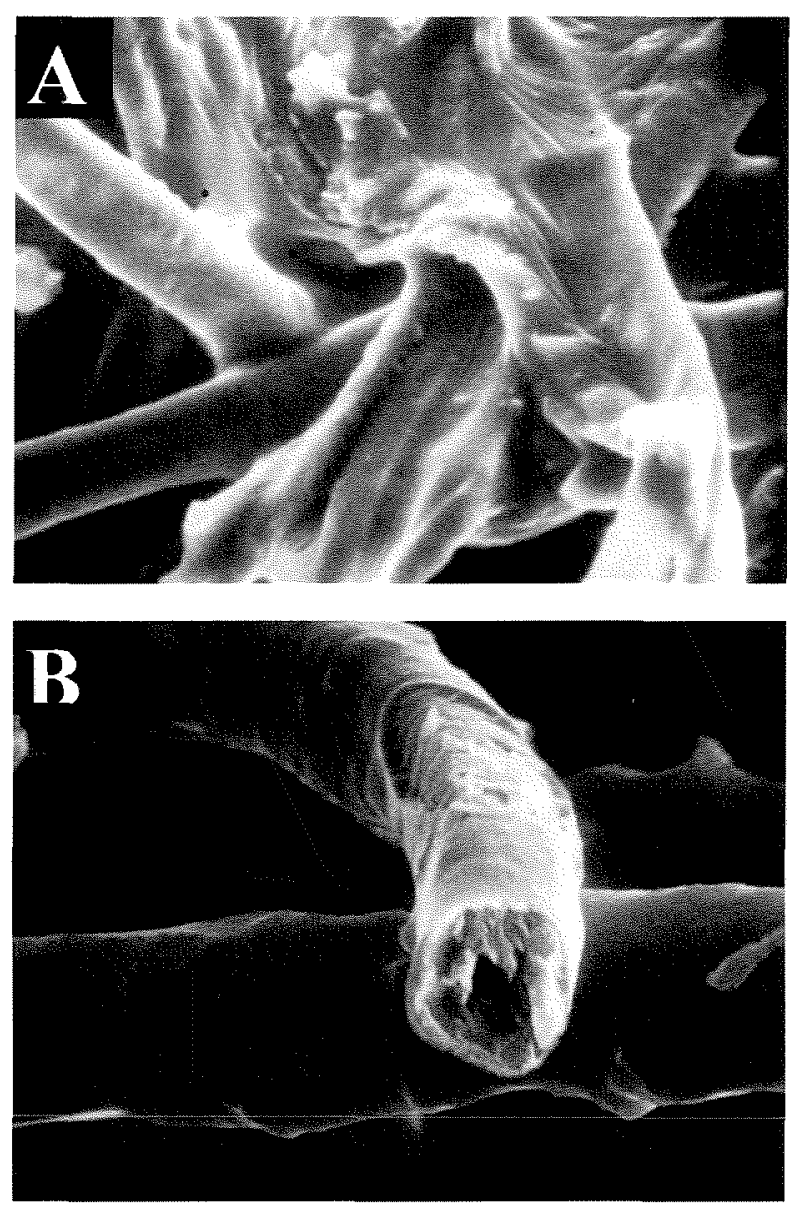

Figure 6 Scanning electron micrograph of the failure surface of the polyurethane composite prepared with unprocessed TMP fiber and tri-functional polyol. Original magnification $\times 200$ (top) and $\times 20$ (bottom).

curs in the triol/TMP composites. The contrast presented by water swelling data is interesting because the observed trends more closely parallel those found for composite MOR. The greater degree of swelling by water for the TMP composites may indicate more ineffective crosslinks created by isocyanate reaction with the cell-wall polymers. This would lead to an interphase structure best characterized as a semi-interpenetrating network, which would create an efficient stress transfer mechanism without significantly altering the desirable properties of the fiber through the development of internal crosslinks.

\section{Scanning Electron Microscopy}

Scanning electron microscopy of failure surfaces was used for direct observation of composite structure, and particularly to evaluate adhesion between the phases. Generally, strong adhesion between the fiber and synthetic urethane was found for all of the composite systems, as suggested from the earlier discussion. The lower magnification view shown in Figure 6(A) clearly illustrates this, showing extensive interaction between the TMP fiber (50\%) and tri-functional polyol. An interesting view is shown in Figure 6(B) that focuses on a local failure for the TMP composite prepared with the tri-functional polyol. The image again shows strong interaction between the fiber and binder, and a distinctive fiber fracture rather than pullout from the matrix. More significantly, a substantial portion of the fiber wall has been removed as a consequence of a related failure that clearly reveals the extensive interphase formation at the fiber surface, and within the interior of the cell wall. This observation substantiates the premise that the fiber/matrix interphase may include network formation with the cell-wall polymers, and that this extensive boundary is important to the overall properties of the urethane composite.

\section{CONCLUSIONS}

Polyurethane composites based on lignocellulosic fibers offer an interesting system with extensive opportunity to manipulate properties using the wide array of raw materials. Mechanical properties of the composite showed that both the fiber type and the synthetic polyol functionality impact performance characteristics of the materials. Unprocessed thermomechanical pulp fibers consistently produced superior properties when compared with composites prepared with recycled newsprint fiber. Further improvements were found for the tri-functional polyol systems. Both dynamic mechanical analysis and swelling experiments suggest the presence of a phase boundary that was important to the development of strength properties. Although the effect of total hydroxy functionality dominates performance characteristics, the structure of the interphase also plays an important role. Increased accessibility to the internal structure of the fiber wall, either through fiber origin or solubility of the synthetic polyol component, was also suspected to be an important factor in determining composite properties. This observation provides some direction for further investigations into the potential engineering of this versatile material system. 


\section{REFERENCES}

1. Sellers, T., Jr. Plywood and Adhesive Technology; Marcel Dekker: New York, 1985.

2. Razi, P. S.; Raman, A.; Portier, R. J Compos Mater 1997, 31, 2391.

3. Raj, R. G.; Kokta, B. V.; Daneault, C. Int I Polym Mater 1989, 12, 239.

4. Kazayawoko, M.; Balatinecz, J. J.; Woodhams, R. T.; Law, S. Int J Polym Mater 1997, 37, 237.

5. Felix, J. M.; Gatenholm, P. J Appl Polym Sci 1991, 42,609 .

6. Liu, F.-P.; Wolcott, M. P.; Gardner, D. J.; Rials, T. G. Compos Interface 1994, 2, 419.

7. Hawke, R. N.; Sun, B. C. H.; Gale, M. R. Forest Prod J 1992, 42, 61 .

8. Milota, M.; Wilson, J. B. Forest Prod J 1985, 35, 44.

9. Rausthauser, J. W.; Haider, K. W.; Hunt, R. N.; Gustavich, W. S. In Proceedings of the 31st International Particleboard/Composite Symposium;
Wolcott, M. P., Ed; Washington State University: Pullman, WA, 1997.

10. Wendler, S. L.; Frazier, C. E. Int J Adhes Adhes $1996,16,179$.

11. Wendler, S. L.; Frazier, C. E. J Appl Polym Sci $1996,61,775$.

12. Marcinko, J. J.; Rinaldi, P. L.; Bao, S. Forest Prod J $1999,49,75$.

13. Wang, X. Ph.D. Dissertation, Michigan Technological University, Houghton, MI, 1991.

14. Rials, T. G.; Wolcott, M. P. J Mater Sci Lett 1998 , 17,317 .

15. Liang, B.-H.; Shaler, S. M.; Mott, L.; Groom, L. Forest Prod J 1994, 44, 47.

16. Groom, L. H.; Shaler, S. M.; Mott, L. In Woodfiber Plastic Composites: Virgin and Recycled Wood Fiber and Polymers for Composites; Proceedings No. 7293, Madison, WI, 1995, pp. 33-40.

17. Birkinshaw, C.; Buggy, M.; Henn, G. G. J Mater Sci Lett $1985,6,113-114$. 